\title{
A NEWSLETTER FROM THE ENGLISH LANGUAGE INSTITUTE
}

\author{
University of Michigan, Ann Arbor
}

The ELI Testing and Certification Office carries on two programs in addition to the preparation of tests. The first is an overseas testing service for testing the English proficiency of non-native speakers while they are yet in their own countries. Having proved itself successful for the University of Michigan, the program was made available to other colleges and universities. In 1965-66, 4072 foreign students were tested at the request of the colleges and universities to which they had applied. 197 colleges and universities in the United States, Canada and Australia used this program, an increase of better than 40\% over 1964-65. The second program is administered by the United States Information Service and offered to students of English outside the United States. These examinations are open only to candidates whose native language is not English. Those who pass the examination are granted The University of Michigan Certificate of Proficiency in English. In 1965-66, 2019 certificates were granted to foreign nationals in 32 different countries-106 of these were "with Honors."

Research and materials development continues to play an important part at the Institute. Preliminary work is being carried on for the creation of advanced materials in English as a foreign language to be used by students who have completed the four regular English Language Institute textbooks. Some work has also been done on beginning materials for those students who have studied little or no English. It's too early to give details but progress is being made. However, nothing will be available for a year or more.

Now that the University of Michigan is on a three term system, the Institute also gives three 15 week intensive courses in English beginning approximately August 28, January 3, and May 2. In addition, there are five 8 week intensive courses August 28, October 24, January 3, February 28, and June 24, none being given during the first half of the spring-summer term. In 1966 the Institute had over 500 students from 51 different countries in these programs. 
The Teacher Education Program in TEFL granted certificates to 67 students from 24 countries. 25 were Americans who planned to teach outside the United States. Most Americans and many foreign students who have the time take the M.A. program. The Certificate program is given in the summer half term and in the fall term; only occasionally in the winter term. 